\title{
Porcine enteric coronaviruses: an updated overview of the pathogenesis, prevalence, and diagnosis
}

\author{
Qiang Liu ${ }^{1} \cdot$ Huai-Yu Wang ${ }^{1}$
}

Received: 18 January 2021 / Accepted: 22 June 2021 / Published online: 12 July 2021

(c) The Author(s), under exclusive licence to Springer Nature B.V. 2021

\begin{abstract}
The recent prevalence of coronavirus $(\mathrm{CoV})$ poses a serious threat to animal and human health. Currently, porcine enteric coronaviruses (PECs), including the transmissible gastroenteritis virus (TGEV), the novel emerging swine acute diarrhoea syndrome coronavirus (SADS-CoV), porcine delta coronavirus (PDCoV), and re-emerging porcine epidemic diarrhoea virus (PEDV), which infect pigs of different ages, have caused more frequent occurrences of diarrhoea, vomiting, and dehydration with high morbidity and mortality in piglets. PECs have the potential for cross-species transmission and are causing huge economic losses in the pig industry in China and the world, which therefore needs to be urgently addressed. Accordingly, this article summarises the pathogenicity, prevalence, and diagnostic methods of PECs and provides an important reference for their improved diagnosis, prevention, and control.
\end{abstract}

Keywords Porcine delta coronavirus · Porcine enteric coronavirus · Porcine epidemic diarrhoea virus $\cdot$ Swine acute diarrhoea syndrome coronavirus · Transmissible gastroenteritis virus

\section{Introduction}

Infectious diseases caused by coronaviruses $(\mathrm{CoVs})$ in recent years, including severe acute respiratory syndrome (SARS), Middle East respiratory syndrome (MERS), and coronavirus disease 2019 (COVID-19), pose a great threat to human and animal health, as they can infect many kinds of mammals and birds (Cui et al. 2019; Liu et al. 2020b). CoVs are the largest single-stranded RNA viruses, belonging to the subfamily Coronavirinae, family Coronaviridae, and order Nidovirales (Su et al. 2016). To date, four genera have been described in the subfamily Coronavirinae, including Alphacoronavirus, Betacoronavirus, Gammacoronavirus, and Deltacoronavirus (Weiss and Navas-Martin 2005). CoVs can cause respiratory and digestive tract infections in humans and animals (Woo et al. 2012). Piglet diarrhoea, mainly caused by CoVs, is one of the most difficult problems in the pig industry worldwide. Currently, four CoVs, transmissible gastroenteritis virus (TGEV), porcine epidemic

Qiang Liu

liuqiang_yyy@163.com

1 Nanchong Key Laboratory of Disease Prevention, Control and Detection in Livestock and Poultry, Nanchong Vocational and Technical College, Nanchong 637131, China diarrhoea virus (PEDV), swine acute diarrhoea syndrome coronavirus (SADS-CoV), and porcine deltacoronavirus (PDCoV), are known to cause intestinal diseases, watery diarrhoea, and high mortality in infected piglets (Yang et al. 2020). Thus, the prevalence of porcine enteric coronaviruses (PECs) poses a great threat to the pig industry in China and the world, given the additional risk of cross-species transmission.

\section{Transmissible gastroenteritis virus}

Transmissible gastroenteritis (TGE) of pigs is a highly contagious digestive tract infection caused by TGEV and characterised by vomiting, severe diarrhoea, dehydration, and high mortality of piglets, within 2 weeks of age (Garwes 1988). The disease was first reported in 1946 in the United States (US), followed by outbreaks in many countries in the Americas, Asia, and Europe (Doyle and Hutchings 1946; Kim et al. 2000; Stevenson et al. 2013). The severity of clinical signs caused by TGEV is inversely proportional to the age of the pig population. Piglets less than 2 weeks of age are the most susceptible to infection, developing vomiting, watery, or slushy diarrhoea, and yellow faeces, often with undigested curd. The piglets lose weight rapidly, become 
dehydrated, and die within 1 week of onset, with mortality rates often reaching $100 \%$. Infected lactating sows show a transient temperature increase, lactation cessation, vomiting, anorexia, and diarrhoea, which last for a short time, and they rarely die, whereas some lactating sows show no clinical signs (Ding et al. 2017; Penzes et al. 2001; Saif 1999). Histopathological changes have been mainly found to occur in the stomach and small intestines of pigs. Microscopic examination has shown that the villi of the small intestine are atrophied, shortened, and even necrotic (Table 1). Histochemical analysis demonstrated that the number of CD3 + T cells, SIgA-positive cells, and dendritic cells were decreased, whereas the number of microfold (M) cells and cell proliferation were increased in the jejunum of TGEVinfected pigs. Moreover, this study also found that the gene copy numbers of Enterobacteriaceae were increased and the number of Lactobacillus was decreased in mucosal scraping samples from TGEV-infected pigs (Xia et al. 2018a, b).

TGEV has a non-segmented, single- and positivestranded RNA genome of $\sim 28.5 \mathrm{~kb}$, and both ends of the genome are 5'-cap and 3'-poly (A) tail structures. The open reading frame (ORF) arrangement is 5'-ORF1a-ORF1bORF2-ORF3a-ORF3b-ORF4-ORF5-ORF6-ORF7-3', with ORF1a and $1 \mathrm{~b}$ occupying two-thirds of the length of the genome and encoding pp1a and pp1b, respectively. ORF2, ORF4, ORF5, and ORF6 encode four structural proteins, including spike protein $(\mathrm{S})$, membrane protein $(\mathrm{M})$, nucleocapsid protein $(\mathrm{N})$, envelope protein $(\mathrm{E})$, and three accessory proteins encoded by ORF3a, ORF3b, and ORF7, respectively (Fig. 1A) (Alonso et al. 2002).

The first step for coronavirus to infect the organism is to recognise and bind to host cell membrane receptor molecules, which then initiate the process of invasion and membrane fusion, and ultimately the release of the viral genome into the infected cell (Fehr and Perlman 2015). The whole process is mediated by the $\mathrm{S}$ protein of coronavirus (Belouzard et al. 2012; Bosch et al. 2003). S protein is a large type I transmembrane glycoprotein, which is functionally divided into two subunits, denoted $\mathrm{S} 1$ and $\mathrm{S} 2$, both of which are responsible for receptor binding and fusion with the cellular membrane, respectively (Belouzard et al. 2012; Bosch et al. 2003). The binding site between the virus and amino peptidase N (APN) receptor is located on the S1 subunit C-terminal domain of the TGEV S protein (Belouzard et al. 2012).

The type of receptor recognised by the S protein of coronavirus and the distribution of the receptor in the host are the key factors that determine the species and tissue tropism for susceptible animals. At present, there are four known functional receptors of coronavirus, namely APN (which is used as a receptor for TGEV) (Delmas et al. 1992), angiotensinconverting enzyme 2 (ACE2; used as a receptor for severe acute respiratory syndrome coronavirus) ( $\mathrm{Li}$ et al. 2003), carcinoembryonic antigen-related cell adhesion molecule 1 (CEACAM1; used as a receptor for murine hepatitis virus) (Williams et al. 1991), and dipeptidyl peptidase 4 (DPP4, also known as CD26; used as a receptor for Middle East respiratory syndrome coronavirus) (Raj et al. 2013).

The functional receptor of TGEV was the first identified among porcine enterocoronavirus (Delmas et al. 1992). The reason why TGEV mainly infects the small intestine might be due to the expression of APN in villous epithelial cells of the small intestine. APN, also known as CD13, is a type II transmembrane glycoprotein, of approximately $150 \mathrm{kDa}$, which is highly expressed in intestinal brush border, renal, and respiratory epithelial cells. Its main functions include peptide metabolism, cell movement, and adhesion (Chen et al. 2012a, b; Mina-Osorio 2008). Studies have confirmed that APN is the functional receptor of TGEV infection, and the regions 36-223 aa, 349-591 aa, and 592-963 aa might be the three main regions binding to TGEV S protein (Ren et al. 2010). Meanwhile, it was also confirmed that TGEV S protein has red blood cell agglutination activity. This process is realised by the combination of the $S$ protein and sialic acid on the surface of red blood cells (Schultze et al. 1996; Schwegmann-Wessels et al. 2003). Studies have shown that TGEV has different affinities for different sialic acids. At present, three kinds of sialic acids have been identified as coronavirus receptors or receptor binding co-factors, namely namely 5 -N-acetylneuraminic acid (Neu5Ac), 5-N-glycolylneuraminic acid (Neu5Gc), and 5-N-acetyl-9-O-acetylneuraminic acid (Neu5,9Ac2). The affinity of TGEV for Neu5Gc is higher than that for Neu5Ac and Neu5,9Ac2 (Krempl et al. 1997; Schwegmann-Wessels and Herrler 2006; Schwegmann-Wessels et al. 2003). Studies have shown that although TGEV infection of cultured cells in vitro does not rely on its sialic acid activity as the basic condition of infection, the infection of gastrointestinal tissues must be combined with sialic acid. Owing to the interaction between TGEV, sialic acid might help itself pass through the sialic acid-rich mucus layer coated on the surfaces of intestinal epithelial cells (Matrosovich et al. 2015; Schwegmann-Wessels et al. 2003). In addition, one study confirmed that epidermal growth factor receptor (EGFR) is used as a cofactor and plays a synergistic role with APN, early in TGEV infection (Hu et al. 2018). TGEV S1 protein interacts with EGFR extracellular receptor binding domain 1 to induce EGFR internalisation and promote APN and EGFR aggregation, which synergically stimulate PI3K/Akt and MEK/ERK1/2 endocytosis signalling pathways in the early stage of TGEV infection and promote TGEV entry (Hu et al. 2018). These findings contribute to the understanding of the mechanisms of TGEV invasion and provide a potential target for the development of new anti-TGEV therapies. Moreover, EGFR play an important role in the regulation of glucose uptake during TGEV infection (Xia et al. 2018a, b). One study found that in IPEC-J2 cells, TGEV infection enhances the expression of caveolin-1, down-regulates 


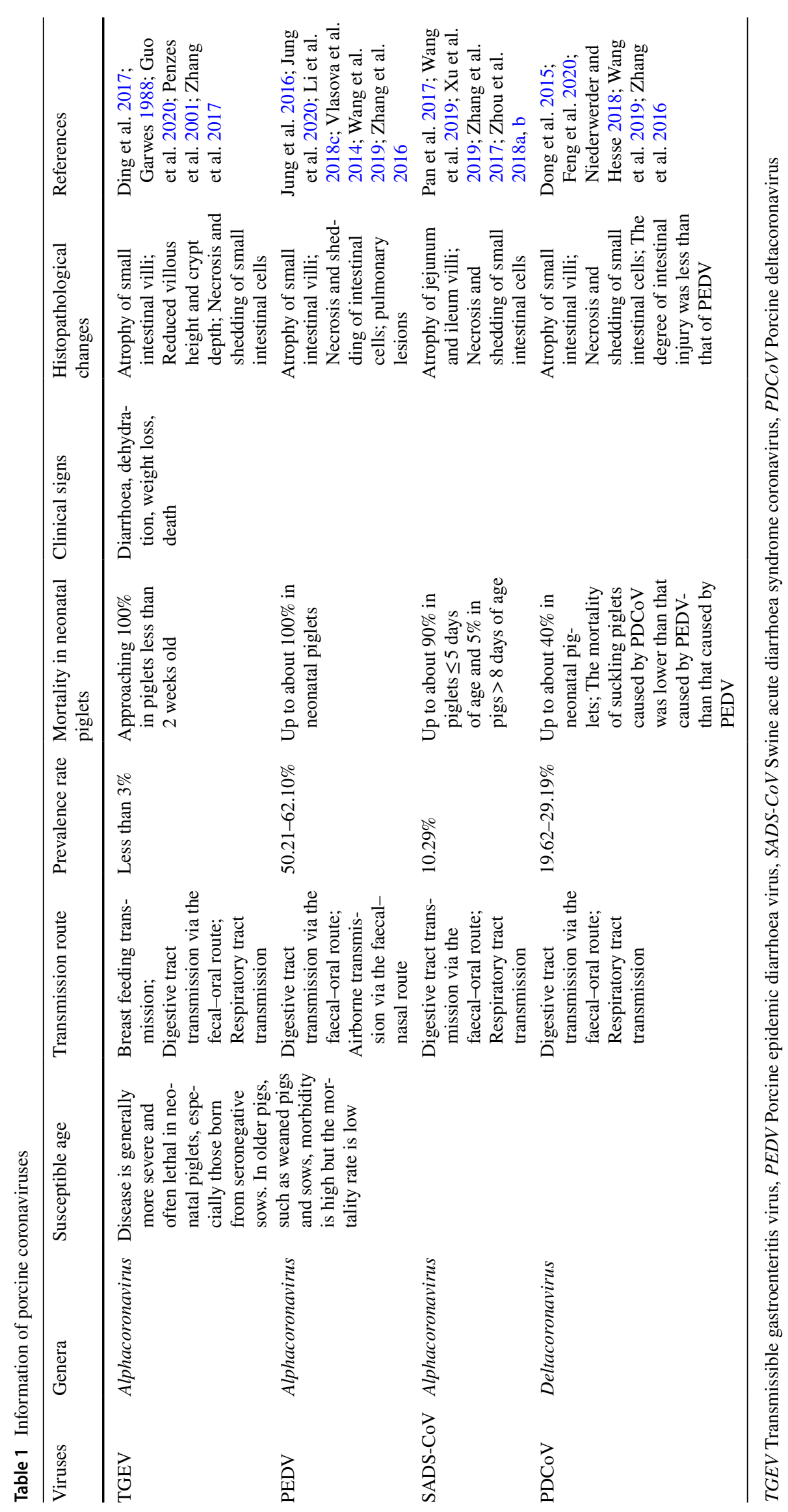



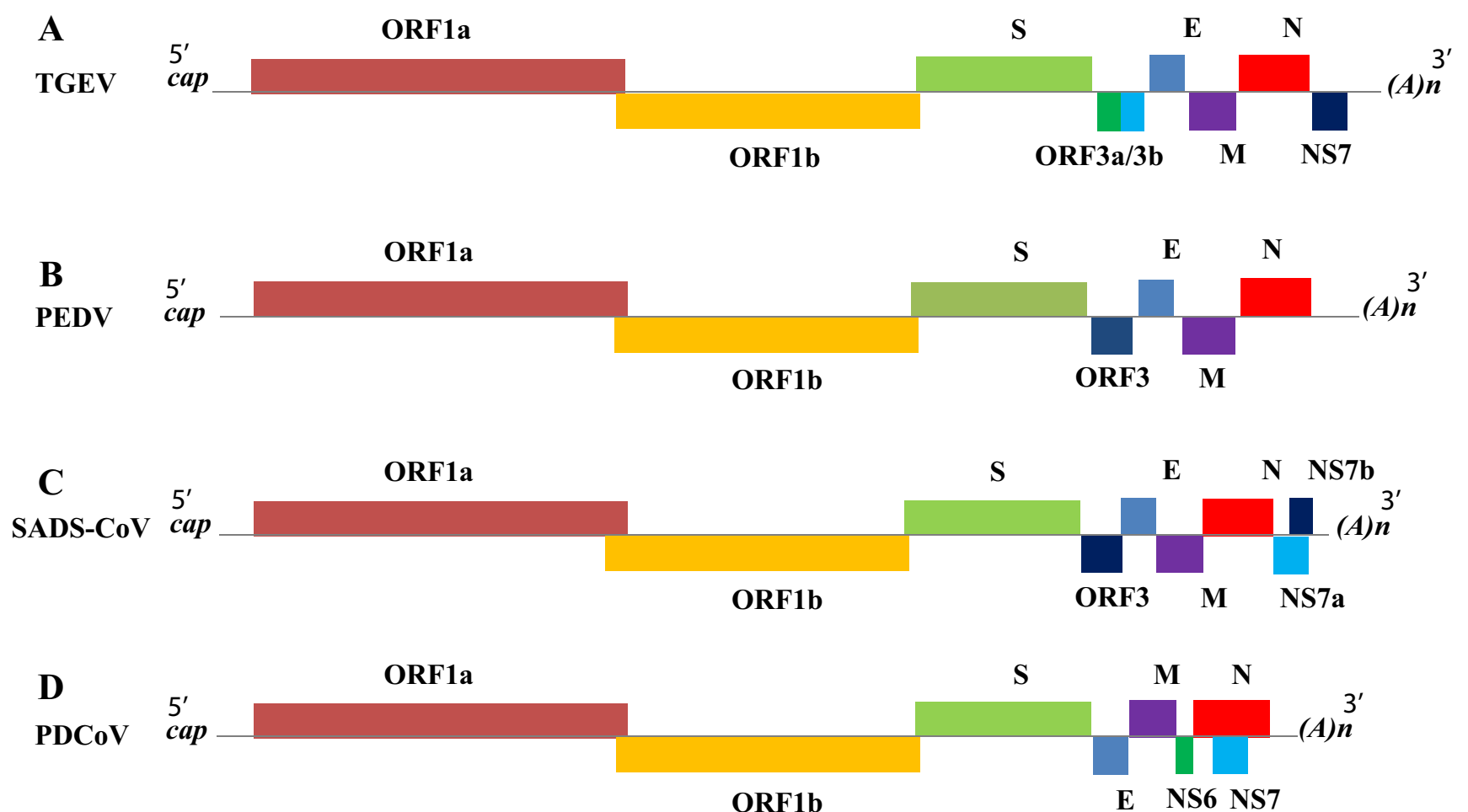

Fig. 1 Genomic structures of porcine enteric coronavirus, including TGEV (A), PEDV (B), SADS-CoV (C), and PDCoV (D). Viral structural genes and presumed accessory genes are shown. There are 5 '-terminal cap structures and 3 '-terminal poly (A) tails at both ends

arginine uptake (which mediates important regulatory functions that affect nutrient metabolism and immune responses), and attenuates cationic amino acid transporter 1 expression to affect nutrient absorption via the induction and activation of phospho-protein kinase $\mathrm{C} \alpha$ (p-PKC $\alpha$ ) and phospho-epidermal growth factor receptor (p-EGFR) (Xia et al. 2018a, b).

The traditional TGEV strains can be further divided into Miller and Purdue subgroups (Zhang et al. 2017). Recently, TGEV was found to have a lower incidence rate than other enteric coronaviruses and is often mixed with other pathogens, such as PEDV and rotavirus (Luo et al. 2020; Zhu et al. 2017a, b, c). A highly virulent TGEV JS2012 strain was isolated from a pig farm in Jiangsu Province, China. Recombinant analysis showed that the strain was a new natural recombinant strain between Miller M6 and Purdue 115, which resulted in $100 \%$ mortality in new-born piglets (Guo et al. 2020).

\section{Porcine epidemic diarrhoea virus}

Porcine epidemic diarrhoea (PED) is a highly contagious intestinal disease caused by PEDV and characterised by acute watery diarrhoea, vomiting, and dehydration ( $\mathrm{Li}$ et al. of the genome. TGEV, transmissible gastroenteritis virus; SADS$\mathrm{CoV}$, swine acute diarrhoea syndrome coronavirus; PDCoV, porcine delta coronavirus; PEDV, porcine epidemic diarrhoea virus

2018c). The first PEDV case was reported on a swine farm in the UK in 1971, but PEDV was first isolated in Belgium in 1978 (Pensaert and de Bouck 1978; Song and Park 2012). In China, PEDV was first discovered in the 1980s and has been reported in some Asian countries, including Japan and South Korea (Kusanagi et al. 1992; Takahashi et al. 1983).

Pigs of all ages can be infected with the virus, but piglets, especially those less than 2 weeks of age, have a high mortality rate of $95 \%$. The clinical signs are very similar to those of TGE, but the mortality rate is slightly lower than that of TGE, and the speed of transmission in pigs is also slower (Jung and Saif 2015). PEDV mainly infects the villous intestinal epithelial cells of the small intestine, resulting in significant atrophy of the intestinal villi (Table 1) (Li et al. 2018c). In the small intestine of PEDV-infected pigs, the tight junction of villous intestinal cells is destroyed, the number of mucins is reduced, and many intestinal cells (such as epithelial cells and goblet cells) are lost, followed by brush border membrane-bound digestive enzymes, such as disaccharidase (lactase, sucrase and maltase), leucine aminopeptidase, and alkaline phosphatase, being significantly decreased, resulting in malabsorption and dyspepsia (Curry et al. 2017; Jung and Saif 2015, 2017; Jung et al. 2006, 2015). Impaired intestinal integrity might lead to the 
ingestion of intraluminal food and bacteria, causing allergic reactions and co-infection, further aggravating the disease (Jung et al. 2020). Additionally, PEDV has also been found to infect alveolar macrophages of the respiratory tract, leading to pulmonary lesions (Park and Shin 2014).

The PEDV genome $(\sim 28 \mathrm{~kb})$ is similar to that of TGEV and contains 5 '-cap structures, a $3^{\prime}$-poly(A) tail, and the ORF arrangement 5'-ORF1a-ORF1b-ORF2-ORF3-ORF4ORF5-ORF6-3'. ORF1a encodes a large polyprotein, pp1a, whereas ORF1b is expressed as a pplab fusion protein via ribosomal frameshifting in the first $2 / 3$ of the $5^{\prime}$ end of the genome. pp1a and pp $1 \mathrm{~b}$ are further processed into 16 nonstructural proteins (NSPs) by the proteinase activity of NSP3 and NSP5. The terminal 1/3 of the genome contains five ORFs, which encode four structural proteins (S, E, M, N), and an accessory protein, respectively (Fig. 1B) (Hou and Wang 2019).

Similar to other enveloped viruses, PEDV also mediates virus adsorption and invasion to cells through its $\mathrm{S}$ protein, and $\mathrm{S}$ protein cleavage is crucial for virus invasion (Deng et al. 2016; Liu et al. 2015; Nam and Lee 2010). in-vitro studies confirmed that cell lines, such as MDCK cells, with over-expression of pAPN could support the replication and continuous passage of PEDV in non-susceptible cells. In contrast, MDCK cells that are neutralised by the pAPN antibody could limit the infection of PEDV (Li et al. 2007). These results suggest that pAPN is a functional receptor for PEDV infection. Similar studies have shown that overexpression or knockdown of pAPN in porcine intestinal epithelial cells (PIECs) by transient expression and siRNA could increase or decrease PEDV infection, respectively (Cong et al. 2015). in-vivo experiments confirmed that although pAPN transgenic mice show no obvious disease signs, PEDV could infect pAPN transgenic mice but could not infect wild-type mice (Park et al. 2015). These studies have shown that pAPN is a functional receptor of PEDVinfected cells. However, several studies have pointed out that pAPN is not a functional receptor for PEDV (Ji et al. 2018; Shirato et al. 2016). The main contradiction is that Vero cells supports PEDV infection and replication, but Vero cells do not express endogenous pAPN (Ji et al. 2018). Moreover, human HeLa cells expressing pAPN and pAPN-positive porcine CPK cells fail to support PEDV infection (Shirato et al. 2016). In vivo experiments using pAPN-knockout transgenic pigs with TGEV or PEDV challenge confirmed that pigs without pAPN could not be infected by TGEV but could still be infected by PEDV (Whitworth et al. 2019). Therefore, further experiments are needed to verify whether an additional cellular receptor is involved in PEDV infection.

Similar to TGEV, PEDV can also bind sialic acid (Deng et al. 2016; Liu et al. 2015). Further studies confirmed that PEDV S1 not only interacts with pAPN through its C-terminal domain, but also interacts with saccharide co-receptor
Neu5Ac through its N-terminal (Deng et al. 2016). Enveloped viruses can invade cells directly by binding to receptors on the cell surface or are capable of being internalised by endocytosis via fusion occurring in the endosomal compartment. In addition, one study demonstrated for the first time that PEDV instantaneously infects nasal epithelial cells (Li et al. 2018b). Dendritic cells (DCs) in the nasal submucosa could extend out dendrites and enter the nasal cavity to absorb PEDV and assist PEDV in crossing the mucosa. DCs carrying PEDV then deliver the virus to $\mathrm{CD} 3+\mathrm{T}$ cells. Via the blood and lymph circulation, virus-carrying CD3 $+\mathrm{T}$ cells reach the intestinal epithelial cells, where infection occurs (Li et al. 2018b). The results of this study revealed a new mechanism by which PEDV could cause intestinal pathogenicity through nasal transmission.

There are two known PEDV genotypes, Genogroup I (GI) and Genogroup II (GII). GII-type can be divided into GII$a$, GII-b, and GII-c subtypes. China and the United States are dominated by the GII strain (Antas and Wozniakowski 2019; Lin et al. 2016). In October 2010, a severe PED epidemic caused by a highly virulent variant of PEDV broke out in southern China, with a mortality rate of $70-100 \%$ (Li et al. 2012; Sun et al. 2012). Ever since that, the detection of highly virulent strains of PEDV has also been reported in other countries, including the United States, Canada, Mexico, Austria, Belgium, France, Germany and Italy (Chen et al. 2012a, b; Ojkic et al. 2015; Tian et al. 2014). Currently, PEDV strains circulating in the US include NON-INDEL (USA/Kansas29/2013) and S-INDEL (USA/OH851/2014), both of which are classified as GII (Antas and Wozniakowski 2019). In experimental infections, the NON-INDEL strains showed higher pathogenicity and mortality (up to 100\%) than S-INDEL strains (mortality rate ranging from 0 to $70 \%$ ), although S INDEL strains are less frequently diagnosed (Vlasova et al. 2014; Wang et al. 2014a, b).

\section{Swine acute diarrhoea syndrome coronavirus}

In 2016-2017, Chinese scientists discovered a new enteric coronavirus in diarrheal pigs from four farms in Guangdong Province, China, and named it SADS-CoV, also known as SeACoV and PEAV (Gong et al. 2017; Pan et al. 2017; Yang et al. 2019a, b). As of May 2017, SADS-CoV had caused approximately 25,000 pig deaths. Gene sequencing and analysis showed that the SADS-CoV genome sequence was more than $95 \%$ consistent with that of a bat coronavirus, HKU2, isolated from the Chinese chrysanthemum bat (found in a cave not far from the pig farm with the SADS-CoV outbreak) in Hong Kong and Guangdong in 2013-2016 (Gong et al. 2017; Pan et al. 2017; Yang et al. 2019a, b). These results confirmed that the novel $\mathrm{CoV}$ originating from bats 
was the pathogen causing fatal diarrhoea in piglets on pig farms in Guangdong in 2016-2017 (Gong et al. 2017; Yang et al. 2019a, b; Zhou et al. 2019b).

The SADS-CoV genome is $\sim 27.2 \mathrm{~kb}$, and the ORF sequence is 5'-ORF1a-ORF1b-ORF2-ORF3-ORF4-ORF5ORF6-ORF7a/b-3'. ORF1a and $1 \mathrm{~b}$ encode pp1a and $\mathrm{pp} 1 \mathrm{~b}$, respectively, within the $5^{\prime}$ terminal end of the SADS-CoV genome, whereas the 3'-terminal region encodes four structural proteins $(\mathrm{S}, \mathrm{E}, \mathrm{M}, \mathrm{N})$ and some genus-specific accessory genes. A putative ORF, which encodes NSP7a and a downstream NSP7b (overlapping NSP7a), is located at the $3^{\prime}$ terminus of the $\mathrm{N}$ gene of the SADS-CoV genome. Both HKU2 and SADS-CoV strains contain NSP7a, whereas NSP7b only exists in SADS-CoV (Fig. 1C) (Lau et al. 2007; Pan et al. 2017; Zhou et al. 2018b).

As a newly discovered porcine enterovirus, the functional receptor of SADS-CoV is also of concern. Compared with that of HKU2-CoV, there are many base insertions or deletions in the genome of SADS-CoV, especially a 75 amino acid substitution and 2 amino acid insertion in the $\mathrm{S}$ protein. This might be related to transformation of the infection spectrum of SADS-CoV (Pan et al. 2017). In addition, it was found that the evolutionary distance between SADS-CoV and human coronavirus 229E / NL63 is close, and SADSCoV and NL63 have similar receptor-binding domains, the latter able to use ACE2 as the invasion receptor, suggesting that SADS-CoV might use ACE2 as a receptor, implying the threat of transspecies transmission to humans (Hofmann et al. 2005; Wang et al. 2018a, b, c). However, SADS-CoV receptor interactions using in vitro infection assays showed that the known coronavirus receptors, including ACE2, DPP4, CEACAM1a, and APN, are not necessary for the entry of SADS-CoV into a variety of mammalian cell lines, such as MDCK cells and HeLa cells (Edwards et al. 2020; Yang et al. 2019a, b; Zhou et al. 2018a, b). Therefore, the host receptors of SADS-CoV need to be further studied.

There are relatively few reports about SADS-CoV, as it has only been detected in the Guangdong and Fujian provinces of China, with a 10\% incidence rate (Li et al. 2018a). The clinical signs of the disease are very similar to those caused by other known PECs, and the main characteristics are vomiting, diarrhoea, and a high mortality rate in newborn piglets (Table 1). After infection with SADS-CoV, the lesions mainly occur in the small intestine, especially in the jejunum and ileum, resulting in thinning of the intestinal wall and the filling of large amounts of yellow watery faeces in the intestinal cavity (Pan et al. 2017; Zhou et al. 2018a, b). SADS-CoV infection leads to the shortening of villi and the destruction of capillaries and the central chylous duct, which might be the main reason for the loss of intestinal function. It should be noted that there is no cross-reaction between SADS-CoV and TGEV, PEDV, or PDCoV, which are currently prevalent in pig farms, suggesting that the existing
PEC vaccine has no cross-protective effect on SADS-CoV infection (Gerdts and Zakhartchouk 2017; Pascual-Iglesias et al. 2019).

\section{Porcine deltacoronavirus}

Porcine deltacoronavirus disease (PDCoVD) of pigs is a new enteric infectious disease mainly caused by PDCoV and characterised by clinical signs such as watery diarrhoea and vomiting (Song et al. 2015). PDCoVD was first reported in Hong Kong, China in 2012, and broke out in the US for the first time in 2014 (Wang et al. 2014a; Woo et al. 2012). Subsequently, it has been reported successively in many countries, including Canada, South Korea, and Vietnam, causing serious economic losses (Janetanakit et al. 2016; Koonpaew et al. 2019; Lee and Lee 2014).

Compared with those of PEDV, the clinical signs caused by PDCoV infection were found to be less sever, and the mortality rate of new-born piglets is 30 to $40 \%$. However, co-infection with PEDV, TGEV, or porcine rotavirus is more common and leads to more serious clinical signs (Marthaler et al. 2014). The histopathological changes caused by PDCoV are similar to those of other PECs, which cause acute necrosis of intestinal epithelial cells and then shrinkage and abscission of intestinal villi, as well as intestinal wall thinning, intestinal dysfunction, and the body's absorption of water decreased, leading to diarrhoea (Table 1) (Pan et al. 2017; Suzuki et al. 2018).

The PDCoV genome is $\sim 25.4 \mathrm{~kb}$ long and has a similar structure to that of other $\mathrm{CoVs}$, with non-coding regions at both ends. The $5^{\prime}$ terminal $3 / 4$ of the genome contains two overlapping ORFs, ORF1a and ORF1b, which encode two polymerase proteins, pp1a and pp1b, respectively, and the remaining genome, encodes four structural proteins (S, E, M, and N). PDCoV also expresses three accessory proteins, NSP6 (between the M and N genes) and NSP7/ NSP7a (within the N gene) (Fig. 1D) (Wang et al. 2019). PDCoV can inhibit the production of interferon (IFN) by using its NSPs to inhibit the body's innate immunity (Fang et al. 2018; Zhu et al. 2017a, b, c). Studies have shown that the NSP5 of PDCoV can inhibit the production of IFN- $\beta$ by cleaving the nuclear factor-kappa B (NF-kB) essential modulator (NEMO) molecule in the IFN signalling pathway and reducing its expression (Zhu et al. 2017a, b, c). Moreover, NSP5 can also reduce the expression of $\mathrm{f}$ signal transducer and activator of transcription 2 (STAT2), which is the key molecule in the JAK-STAT signalling pathway, to inhibit the activation of interferon downstream signalling molecules and the transcription of antiviral genes in porcine kidney epithelial (PK-15) cells, thus antagonising the body's innate immunity and promoting its infection and replication (Zhu et al. 2017a, b, c). In addition, the accessory 
protein NS6 can inhibit the recognition of RNA mediated by RIG-I/MDA5 by interacting with RIG-I/MDA5 in cells, thereby inhibiting intracellular beta interferon production to antagonise innate immune processes mediated by RIG-I-like pattern recognition receptors (Fang et al. 2018).

The S protein of PDCoV plays an important role in the binding of viruses to cell receptors and mediating viral invasion and infection (Wang et al. 2018a, b, c). The usage of $\mathrm{PDCoV}$ receptors is controversial. On the one hand, studies have shown that pAPN is a functional receptor for PDCoV infection (Wang et al. 2018a, b, c). Wang et al. proved that in non-susceptible cells, such as Vero and BHK21 cells, which could not be infected by PDCoV, overexpression of pAPN could lead to infection by PDCoV (Wang et al. 2018a, b, c). According to studies, PDCoV could also use chicken APN, human APN, and feline APN as receptors (Jung et al. 2017; Li et al. 2018b). The specific mechanism by which PDCoV can use APN of different species as receptors might be that PDCoV S protein binds to the phylogenetically conserved catalytic domain of APN from different species ( $\mathrm{Li}$ et al. 2018b). These research results suggest that the risk of PDCoV cross-species transmission and its potential threat to human health should be taken seriously. However, some studies have shown that cell lines, such as porcine intestinal epithelial cells (IPI)-2I cells, lacking pAPN retain permissiveness to PDCoV infection (Zhu et al. 2018). Moreover, after pAPN antibody treatment or the knockout of pAPN, PDCoV infection could only be slightly inhibited in IPI-2I cells (Zhu et al. 2018). Further, an in vivo study constructed double-gene knockout pigs with the deletion of APN/CD163 and then challenged them with PDCoV (Xu et al. 2020). The results showed that pigs without pAPN could be infected by PDCoV, but the efficiency of PDCoV infection was reduced (Xu et al. 2020). The results of this study indicated that DKO pigs were less sensitive to PDCoV, providing direct in vivo evidence for pAPN, which is involved in PDCoV infection, as one of the PDCoV receptors but not a critical functional receptor for PDCoV infection. In addition, swine testicular (STs) with a knockout of pAPN expression retain a small capacity to support PDCoV infection. This result suggested that in addition to pAPN, PDCoV infection might also require the involvement of a second receptor, the function of which is independent of pAPN (Stoian et al. 2020; Wang et al. 2018a, b, c).

PDCoV has been found in China, the US, South Korea, and Thailand (He et al. 2020; Zhang 2016). In these countries, the prevalence of PDCoV is lower than that of PEDV. Co-infection with other enteric pathogens, such as PEDV, is common in PDCoV-positive samples, and 56\% of diarrhoeal pigs infected with PDCoV were found to be infected with PEDV (Dong et al. 2015; Feng et al. 2020). By comparing the existing PDCoV genome sequences, it was found that the nucleic acid sequences of PDCoV strains isolated from different countries (e.g. China, the USA and South Korea) are highly homologous. They are also highly homologous to the original sequence HKU15, indicating that the evolution of PDCOV is relatively conservative (Wang et al. 2016).

\section{Diagnostic methods for porcine enteric coronavirus disease}

Since the clinical signs and pathological characteristics of the four kinds of PECs are similar, differential diagnoses cannot only be made according to the necropsy results but also depend on accurate laboratory diagnosis. The main methods for laboratory diagnosis of pathogens include virus isolation and culture, observation of cytopathy, immunofluorescence, immunohistochemistry, in-situ hybridisation, electron microscopy, and polymerase chain reaction (PCR) (Zhang 2016). These traditional and emerging technologies provide important detection methods for investigating PEC diseases, but they are time-consuming, laborious, and unsuitable for early and rapid PEC detection. Currently, various PCR methods have been widely used to diagnose individual PEC infections. In 2011, Li et al. established a real-time reverse transcription loop-mediated isothermal amplification method based on the conserved $\mathrm{N}$ gene of the TGEV for rapid TGEV diagnosis ( $\mathrm{Li}$ and Ren 2011). In 2018, Wang et al. developed a real-time reverse transcription recombinase polymerase amplification assay PEDV detection based on the $\mathrm{N}$ gene (Wang et al. 2018a, b, c), and Zhou et al. designed a TaqMan-based real-time RT-PCR assay based on the conserved region within the $\mathrm{N}$ gene of the viral genome, to detect SADS-CoV (Zhou et al. 2018a). In 2015, Song et al. reported a nested RT-PCR method for PDCoV detection based on the $\mathrm{N}$ gene sequence of the PDCoV HKU15 strain (Song et al. 2015). In addition, various PCR-based design methods have also been widely used to diagnose co-infections of PECs. In 2017, Zhang et al. designed two pairs of primers based on the $\mathrm{M}$ gene sequences of PEDV and PDCoV and established two single-plex RT-iiPCR tests and a duplex real-time RT-PCR test (Zhang 2016). In 2017, Zhu et al. established a nanoparticle-associated PCR assay for the detection of TGEV and PEDV using two pairs of primers designed based on the $\mathrm{N}$ gene sequences of TGEV and PEDV (Zhu et al. 2017a, b, c). Based on the highly conserved regions of the $\mathrm{N}$ gene of TGEV, the $\mathrm{M}$ gene of PEDV, the $\mathrm{M}$ gene of PDCoV, and $\mathrm{N}$ genes of SADS-CoV, a TaqMan-probe-based multiplex real-time RT-qPCR assay was also designed and used to detect these pathogens in clinical samples with single or co-infections (Huang et al. 2019).

Serological methods are also commonly used to detect viral infections. Since the immune system of piglets is not well developed, serological methods for detecting antibodies against PECs are not suitable for rapid and early 
detection (Fu et al. 2020). However, the combination of serological methods and PCR-based detection technology can complement each other and improve the detection rate. To detect latent infectious animals in particular, the enzyme-linked immunosorbent assay (ELISA) is regarded as the most sensitive and specific method for serum antibody detection. In 2013, Zou et al. described a phageELISA, based on an $M$ protein-binding peptide, to differentiate TGEV from other CoVs (Zou et al. 2013). In 2019, Chang et al. designed an ELISA for PEDV antibody detection based on recombinant trimeric full-length and truncated spike proteins (Chang et al. 2019). In 2017, Luo et al. reported an indirect ELISA based on a recombinant $\mathrm{M}$ protein for the detection of PDCoV IgG antibodies (Luo et al. 2017). In 2020, Malbec et al. developed a multiplex immunoassay for the differential serodiagnosis of PEDV, TGEV, and PDCoV based on virus-specific recombinant S1 proteins printed in an array of spots at the bottom of a 96-well microplate (Malbec et al. 2020). In addition, other serum methods have often been used to detect PECs. In 2020, Liu et al. reported a rapid immunochromatographic strip test for the detection of PEDV-specific secretory immunoglobulin A in colostrum (Liu et al. 2020a).

\section{Future perspectives}

Although TGEV and other PECs have been circulating in pig populations for decades, PEDV, PDCoV, and SADS$\mathrm{CoV}$ are regarded as new CoVs, and they were all first detected in Chinese pig populations (Fu et al. 2020; Lee 2015; Lee and Lee 2014). To date, PEDV variant strains have become prevalent in Asia, North America, and Europe, but no other country has reported SADS-CoV, apart from China (Yang et al. 2020). Sequence analyses have shown that PEDV and SADS-CoV might have originated from bat $\mathrm{CoV}$, whereas PDCoV, which also demonstrates the cross-species transmission characteristics of $\mathrm{CoV}$, originated from sparrow $\mathrm{CoV}$ (Cui et al. 2019; He et al. 2020; Yang et al. 2019a, b; Zhou et al. 2019a). Therefore, it is of great significance for animal and human health safety to continue to conduct large-scale epidemiological investigations. Currently, there are more studies on PEDV than on the other three PECs, and different vaccines have been developed, but further improvement is needed in terms of their efficacy and safety. The prevention and control of PEC diseases mainly depend on the management levels of pig farms, with an emphasis on improving biosafety measures within and between farms. Rapid, accurate, and practical detection methods are of great significance for the monitoring, prevention, and control of
PECs, and new detection methods are still worth further development.

Acknowledgements This study was supported by grants from the Nanchong Vocational and Technical College for basic scientific research (no. ZRA1904 and no. NZYBZ2002) and the Applied Technology Research and Development Programme of Nanchong (no. 19YFZJ0027).

Author contributions LQ and WHY reviewed the literature, and LQ drafted the manuscript.

Data availability Data sharing is not applicable to this article as no new data were created or analysed in this study.

\section{Declarations}

Ethical statement No ethical approval was required as this is a review article with no original research data.

Consent to participate Not applicable.

Consent for publication Not applicable.

Conflict of interest The authors declare no conflicts of interest.

\section{References}

Alonso S, Izeta A, Sola I, Enjuanes L (2002) Transcription regulatory sequences and mRNA expression levels in the coronavirus transmissible gastroenteritis virus. J Virol 76:1293-1308

Antas M, Wozniakowski G (2019) Current status of porcine epidemic diarrhoea (PED) in european pigs. J Vet Res 63:465-470

Belouzard S, Millet JK, Licitra BN, Whittaker GR (2012) Mechanisms of coronavirus cell entry mediated by the viral spike protein. Viruses 4(6):1011-1033

Bosch BJ, van der Zee R, de Haan CA, Rottier PJ (2003) The coronavirus spike protein is a class I virus fusion protein: structural and functional characterization of the fusion core complex. J Virol 77(16):8801-8811

Chang CY, Peng JY, Cheng YH, Chang YC, Wu YT, Tsai PS, Chiou HY, Jeng CR, Chang HW (2019) Development and comparison of enzyme-linked immunosorbent assays based on recombinant trimeric full-length and truncated spike proteins for detecting antibodies against porcine epidemic diarrhea virus. BMC Vet Res 15:421

Chen F, Pan Y, Zhang X, Tian X, Wang D, Zhou Q, Song Y, Bi Y (2012a) Complete genome sequence of a variant porcine epidemic diarrhea virus strain isolated in China. J Virol 86:12448

Chen L, Lin YL, Peng G, Li F (2012b) Structural basis for multifunctional roles of mammalian aminopeptidase N. Proc Natl Acad Sci U S A 109(44):17966-17971

Cong Y, Li X, Bai Y, Lv X, Herrler G, Enjuanes L, Zhou X, Qu B, Meng F, Cong C, Ren X, Li G (2015) Porcine aminopeptidase N mediated polarized infection by porcine epidemic diarrhea virus in target cells. Virology 478:1-8

Cui J, Li F, Shi ZL (2019) Origin and evolution of pathogenic coronaviruses. Nat Rev Microbiol 17:181-192

Curry SM, Schwartz KJ, Yoon KJ, Gabler NK, Burrough ER (2017) Effects of porcine epidemic diarrhea virus infection on 
nursery pig intestinal function and barrier integrity. Vet Microbiol 211:58-66

Delmas B, Gelfi J, L'Haridon R, Vogel LK, Sjöström H, Norén O, Laude H (1992) Aminopeptidase $\mathrm{N}$ is a major receptor for the entero-pathogenic coronavirus TGEV. Nature 357(6377):417-420

Deng F, Ye G, Liu Q, Navid MT, Zhong X, Li Y, Wan C, Xiao S, He Q, Fu ZF, Peng G (2016) Identification and comparison of receptor binding characteristics of the spike protein of two porcine epidemic diarrhea virus strains. Viruses 8(3):55

Ding Z, An K, Xie L, Wu W, Zhang R, Wang D, Fang Y, Chen H, Xiao S, Fang L (2017) Transmissible gastroenteritis virus infection induces NF-kappaB activation through RLR-mediated signaling. Virology 507:170-178

Dong N, Fang L, Zeng S, Sun Q, Chen H, Xiao S (2015) Porcine deltacoronavirus in Mainland China. Emerg Infect Dis 21:2254-2255

Doyle LP, Hutchings LM (1946) A transmissible gastroenteritis in pigs. J Am Vet Med Assoc 108:257-259

Edwards CE, Yount BL, Graham RL, Leist SR, Hou YJ, Dinnon KH 3rd, Sims AC, Swanstrom J, Gully K, Scobey TD, Cooley MR, Currie CG, Randell SH, Baric RS (2020) Swine acute diarrhea syndrome coronavirus replication in primary human cells reveals potential susceptibility to infection. Proc Natl Acad Sci U S A 117(43):26915-26925

Fang P, Fang L, Ren J, Hong Y, Liu X, Zhao Y, Wang D, Peng G, Xiao S (2018) Porcine deltacoronavirus accessory protein NS6 antagonizes interferon beta production by interfering with the binding of RIG-I/MDA5 to double-stranded RNA. J Virol 92(15):e00712-e718

Fehr AR, Perlman S (2015) Coronaviruses: an overview of their replication and pathogenesis. Methods Mol Biol 1282:1-23

Feng Y, Xu Z, Zhu L (2020) Prevalence and phylogenetic analysis of porcine deltacoronavirus in Sichuan province, China. Arch Virol 165:2883-2889

Fu Y, Li B, Liu G (2020) Rapid and efficient detection methods of pathogenic swine enteric coronaviruses. Appl Microbiol Biotechnol 104:6091-6100

Garwes DJ (1988) Transmissible gastroenteritis. Vet Rec 122:462-463

Gerdts V, Zakhartchouk A (2017) Vaccines for porcine epidemic diarrhea virus and other swine coronaviruses. Vet Microbiol 206:45-51

Gong L, Li J, Zhou Q, Xu Z, Chen L, Zhang Y, Xue C, Wen Z, Cao Y (2017) A new Bat-HKU2-like coronavirus in swine, China, 2017. Emerg Infect Dis 23:1607-1609

Guo R, Fan B, Chang X, Zhou J, Zhao Y, Shi D, Yu Z, He K, Li B (2020) Characterization and evaluation of the pathogenicity of a natural recombinant transmissible gastroenteritis virus in China. Virology 545:24-32

He WT, Ji X, He W, Dellicour S, Wang S, Li G, Zhang L, Gilbert M, Zhu H, Xing G, Veit M, Huang Z, Han GZ, Huang Y, Suchard MA, Baele G, Lemey P, Su S (2020) Genomic epidemiology, evolution, and transmission dynamics of porcine deltacoronavirus. Mol Biol Evol 37:2641-2654

Hofmann H, Pyrc K, van der Hoek L, Geier M, Berkhout B, Pöhlmann S (2005) Human coronavirus NL63 employs the severe acute respiratory syndrome coronavirus receptor for cellular entry. Proc Natl Acad Sci U S A 102(22):7988-7993

Hou Y, Wang Q (2019) Emerging highly virulent porcine epidemic diarrhea virus: molecular mechanisms of attenuation and rational design of live attenuated vaccines. Int J Mol Sci 20:5478

Hu W, Zhang S, Shen Y, Yang Q (2018) Epidermal growth factor receptor is a co-factor for transmissible gastroenteritis virus entry. Virology 521:33-43

Huang X, Chen J, Yao G, Guo Q, Wang J, Liu G (2019) A TaqManprobe-based multiplex real-time RT-qPCR for simultaneous detection of porcine enteric coronaviruses. Appl Microbiol Biotechnol 103:4943-4952

Janetanakit T, Lumyai M, Bunpapong N, Boonyapisitsopa S, Chaiyawong S, Nonthabenjawan N, Kesdaengsakonwut S, Amonsin A (2016) Porcine deltacoronavirus, Thailand, 2015. Emerg Infect Dis 22:757-759

Ji CM, Wang B, Zhou J, Huang YW (2018) Aminopeptidase-N-independent entry of porcine epidemic diarrhea virus into Vero or porcine small intestine epithelial cells. Virology 517:16-23

Jung K, Ahn K, Chae C (2006) Decreased activity of brush border membrane-bound digestive enzymes in small intestines from pigs experimentally infected with porcine epidemic diarrhea virus. Res Vet Sci 81(3):310-315

Jung K, Eyerly B, Annamalai T, Lu Z, Saif LJ (2015) Structural alteration of tight and adherens junctions in villous and crypt epithelium of the small and large intestine of conventional nursing piglets infected with porcine epidemic diarrhea virus. Vet Microbiol 177(3-4):373-378

Jung K, Hu H, Saif LJ (2017) Calves are susceptible to infection with the newly emerged porcine deltacoronavirus, but not with the swine enteric alphacoronavirus, porcine epidemic diarrhea virus. Arch Virol 162(8):2357-2362

Jung K, Saif LJ (2015) Porcine epidemic diarrhea virus infection: Etiology, epidemiology, pathogenesis and immunoprophylaxis. Vet J 204:134-143

Jung K, Saif LJ (2017) Goblet cell depletion in small intestinal villous and crypt epithelium of conventional nursing and weaned pigs infected with porcine epidemic diarrhea virus. Res Vet Sci 110:12-15

Jung K, Hu H, Saif LJ (2016) Porcine deltacoronavirus infection: Etiology, cell culture for virus isolation and propagation, molecular epidemiology and pathogenesis. Virus Res 226:50-59

Jung K, Saif LJ, Wang Q (2020) Porcine epidemic diarrhea virus (PEDV): an update on etiology, transmission, pathogenesis, and prevention and control. Virus Res 286:198045

Kim L, Chang KO, Sestak K, Parwani A, Saif LJ (2000) Development of a reverse transcription-nested polymerase chain reaction assay for differential diagnosis of transmissible gastroenteritis virus and porcine respiratory coronavirus from feces and nasal swabs of infected pigs. J Vet Diagn Invest 12:385-388

Koonpaew S, Teeravechyan S, Frantz PN, Chailangkarn T, Jongkaewwattana A (2019) PEDV and PDCoV pathogenesis: the interplay between host innate immune responses and porcine enteric coronaviruses. Front Vet Sci 6:34

Krempl C, Schultze B, Laude H, Herrler G (1997) Point mutations in the $\mathrm{S}$ protein connect the sialic acid binding activity with the enteropathogenicity of transmissible gastroenteritis coronavirus. J Virol 71(4):3285-3287

Kusanagi K, Kuwahara H, Katoh T, Nunoya T, Ishikawa Y, Samejima $\mathrm{T}$, Tajima M (1992) Isolation and serial propagation of porcine epidemic diarrhea virus in cell cultures and partial characterization of the isolate. J Vet Med Sci 54:313-318

Lau SK, Woo PC, Li KS, Huang Y, Wang M, Lam CS, Xu H, Guo R, Chan KH, Zheng BJ, Yuen KY (2007) Complete genome sequence of bat coronavirus HKU2 from Chinese horseshoe bats revealed a much smaller spike gene with a different evolutionary lineage from the rest of the genome. Virology 367:428-439

Lee C (2015) Porcine epidemic diarrhea virus: An emerging and reemerging epizootic swine virus. Virol J 12:193

Lee S, Lee C (2014) Complete genome characterization of Korean porcine deltacoronavirus strain KOR/KNU14-04/2014. Genome Announc 2:e01191-14

Li P, Ren X (2011) Reverse transcription loop-mediated isothermal amplification for rapid detection of transmissible gastroenteritis virus. Curr Microbiol 62:1074-1080 
Li W, Moore MJ, Vasilieva N, Sui J, Wong SK, Berne MA, Somasundaran M, Sullivan JL, Luzuriaga K, Greenough TC, Choe H, Farzan M (2003) Angiotensin-converting enzyme 2 is a functional receptor for the SARS coronavirus. Nature 426(6965):450-454

Li BX, Ge JW, Li YJ (2007) Porcine aminopeptidase N is a functional receptor for the PEDV coronavirus. Virology 365(1):166-172

Li W, Li H, Liu Y, Pan Y, Deng F, Song Y, Tang X, He Q (2012) New variants of porcine epidemic diarrhea virus, China, 2011. Emerg Infect Dis 18:1350-1353

Li K, Li H, Bi Z, Gu J, Gong W, Luo S, Zhang F, Song D, Ye Y, Tang Y (2018a) Complete genome sequence of a novel swine acute diarrhea syndrome coronavirus, CH/FJWT/2018, isolated in Fujian, China, in 2018. Microbiol Resour Announc 7:e01259-18

Li W, Hulswit RJG, Kenney SP, Widjaja I, Jung K, Alhamo MA, van Dieren B, van Kuppeveld FJM, Saif LJ, Bosch BJ (2018b) Broad receptor engagement of an emerging global coronavirus may potentiate its diverse cross-species transmissibility. Proc Natl Acad Sci U S A 115(22):E5135-E5143

Li Y, Wu Q, Huang L, Yuan C, Wang J, Yang Q (2018c) An alternative pathway of enteric PEDV dissemination from nasal cavity to intestinal mucosa in swine. Nat Commun 9:3811

Lin CM, Saif LJ, Marthaler D, Wang Q (2016) Evolution, antigenicity and pathogenicity of global porcine epidemic diarrhea virus strains. Virus Res 226:20-39

Liu C, Tang J, Ma Y, Liang X, Yang Y, Peng G, Qi Q, Jiang S, Li J, Du L, Li F (2015) Receptor usage and cell entry of porcine epidemic diarrhea coronavirus. J Virol 89(11):6121-6125

Liu J, Gao R, Shi H, Cong G, Chen J, Zhang X, Shi D, Cao L, Wang X, Zhang J, Ji Z, Jing Z, Feng L (2020a) Development of a rapid immunochromatographic strip test for the detection of porcine epidemic diarrhea virus specific SIgA in colostrum. J Virol Methods 279:113855

Liu Q, Xu K, Wang X, Wang W (2020b) From SARS to COVID19: What lessons have we learned? J Infect Public Health 13:1611-1618

Luo SX, Fan JH, Opriessnig T, Di JM, Liu BJ, Zuo YZ (2017) Development and application of a recombinant $M$ protein-based indirect ELISA for the detection of porcine deltacoronavirus $\mathrm{IgG}$ antibodies. J Virol Methods 249:76-78

Luo L, Chen J, Li X, Qiao D, Wang Z, Wu X, Du Q, Tong D, Huang Y (2020) Establishment of method for dual simultaneous detection of PEDV and TGEV by combination of magnetic micro-particles and nanoparticles. J Infect Chemother 26:523-526

Malbec R, Kimpston-Burkgren K, Vandenkoornhuyse E, Olivier C, Souplet V, Audebert C, Carrillo-Avila JA, Baum D, GimenezLirola L (2020) Agrodiag PorCoV: a multiplex immunoassay for the differential diagnosis of porcine enteric coronaviruses. $\mathbf{J}$ Immunol Methods 483:112808

Marthaler D, Raymond L, Jiang Y, Collins J, Rossow K, Rovira A (2014) Rapid detection, complete genome sequencing, and phylogenetic analysis of porcine deltacoronavirus. Emerg Infect Dis 20:1347-1350

Matrosovich M, Herrler G, Klenk HD (2015) Sialic acid receptors of viruses. Top Curr Chem 367:1-28

Mina-Osorio P (2008) The moonlighting enzyme CD13: old and new functions to target. Trends Mol Med 14(8):361-371

Nam E, Lee C (2010) Contribution of the porcine aminopeptidase $\mathrm{N}$ (CD13) receptor density to porcine epidemic diarrhea virus infection. Vet Microbiol 144(1-2):41-50

Niederwerder MC, Hesse RA (2018) Swine enteric coronavirus disease: a review of 4 years with porcine epidemic diarrhoea virus and porcine deltacoronavirus in the United States and Canada. Transbound Emerg Dis 65(3):660-675

Ojkic D, Hazlett M, Fairles J, Marom A, Slavic D, Maxie G, Alexandersen S, Pasick J, Alsop J, Burlatschenko S (2015) The first case of porcine epidemic diarrhea in Canada. Can Vet J 56:149-152
Pan Y, Tian X, Qin P, Wang B, Zhao P, Yang YL, Wang L, Wang D, Song Y, Zhang X, Huang YW (2017) Discovery of a novel swine enteric alphacoronavirus (SeACoV) in southern China. Vet Microbiol 211:15-21

Park JE, Shin HJ (2014) Porcine epidemic diarrhea virus infects and replicates in porcine alveolar macrophages. Virus Res 191:143-152

Park JE, Park ES, Yu JE, Rho J, Paudel S, Hyun BH, Yang DK, Shin HJ (2015) Development of transgenic mouse model expressing porcine aminopeptidase $\mathrm{N}$ and its susceptibility to porcine epidemic diarrhea virus. Virus Res 197:108-115

Pascual-Iglesias A, Sanchez CM, Penzes Z, Sola I, Enjuanes L, Zuniga S (2019) Recombinant chimeric transmissible gastroenteritis virus (TGEV) - porcine epidemic diarrhea virus (PEDV) virus provides protection against virulent PEDV. Viruses 11:682

Pensaert MB, de Bouck P (1978) A new coronavirus-like particle associated with diarrhea in swine. Arch Virol 58:243-247

Penzes Z, Gonzalez JM, Calvo E, Izeta A, Smerdou C, Mendez A, Sanchez CM, Sola I, Almazan F, Enjuanes L (2001) Complete genome sequence of transmissible gastroenteritis coronavirus PUR46-MAD clone and evolution of the purdue virus cluster. Virus Genes 23:105-118

Raj VS, Mou H, Smits SL, Dekkers DH, Müller MA, Dijkman R, Muth D, Demmers JA, Zaki A, Fouchier RA, Thiel V, Drosten C, Rottier PJ, Osterhaus AD, Bosch BJ, Haagmans BL (2013) Dipeptidyl peptidase 4 is a functional receptor for the emerging human coronavirus-EMC. Nature 495(7440):251-254

Ren X, Li G, Liu B (2010) Binding characterization of determinants in porcine aminopeptidase $\mathrm{N}$, the cellular receptor for transmissible gastroenteritis virus. J Biotechnol 150(1):202-206

Saif LJ (1999) Comparative pathogenesis of enteric viral infections of swine. Adv Exp Med Biol 473:47-59

Schultze B, Krempl C, Ballesteros ML, Shaw L, Schauer R, Enjuanes L, Herrler G (1996) Transmissible gastroenteritis coronavirus, but not the related porcine respiratory coronavirus, has a sialic acid (N-glycolylneuraminic acid) binding activity. J Virol 70(8):5634-5637

Schwegmann-Wessels C, Zimmer G, Schröder B, Breves G, Herrler G (2003) Binding of transmissible gastroenteritis coronavirus to brush border membrane sialoglycoproteins. J Virol 77(21):11846-11848

Schwegmann-Wessels C, Herrler G (2006) Sialic acids as receptor determinants for coronaviruses. Glycoconj J 23(1-2):51-58

Shirato K, Maejima M, Islam MT, Miyazaki A, Kawase M, Matsuyama S, Taguchi F (2016) Porcine aminopeptidase $\mathrm{N}$ is not a cellular receptor of porcine epidemic diarrhea virus, but promotes its infectivity via aminopeptidase activity. J Gen Virol 97(10):2528-2539

Song D, Park B (2012) Porcine epidemic diarrhoea virus: a comprehensive review of molecular epidemiology, diagnosis, and vaccines. Virus Genes 44:167-175

Song D, Zhou X, Peng Q, Chen Y, Zhang F, Huang T, Zhang T, Li A, Huang D, Wu Q, He H, Tang Y (2015) Newly emerged porcine deltacoronavirus associated with diarrhoea in swine in China: identification, prevalence and full-length genome sequence analysis. Transbound Emerg Dis 62:575-580

Stevenson GW, Hoang H, Schwartz KJ, Burrough ER, Sun D, Madson D, Cooper VL, Pillatzki A, Gauger P, Schmitt BJ, Koster LG, Killian ML, Yoon KJ (2013) Emergence of porcine epidemic diarrhea virus in the United States: clinical signs, lesions, and viral genomic sequences. J Vet Diagn Invest 25:649-654

Stoian A, Rowland RRR, Petrovan V, Sheahan M, Samuel MS, Whitworth KM, Wells KD, Zhang J, Beaton B, Cigan M, Prather RS (2020) The use of cells from ANPEP knockout pigs to evaluate 
the role of aminopeptidase $\mathrm{N}(\mathrm{APN})$ as a receptor for porcine deltacoronavirus (PDCoV). Virology 541:136-140

Su S, Wong G, Shi W, Liu J, Lai ACK, Zhou J, Liu W, Bi Y, Gao GF (2016) Epidemiology, genetic recombination, and pathogenesis of coronaviruses. Trends Microbiol 24:490-502

Sun RQ, Cai RJ, Chen YQ, Liang PS, Chen DK, Song CX (2012) Outbreak of porcine epidemic diarrhea in suckling piglets, China. Emerg Infect Dis 18:161-163

Suzuki T, Shibahara T, Imai N, Yamamoto T, Ohashi S (2018) Genetic characterization and pathogenicity of Japanese porcine deltacoronavirus. Infect Genet Evol 61:176-182

Takahashi K, Okada K, Ohshima K (1983) An outbreak of swine diarrhea of a new-type associated with coronavirus-like particles in Japan. Nihon Juigaku Zasshi 45:829-832

Tian PF, Jin YL, Xing G, Qv LL, Huang YW, Zhou JY (2014) Evidence of recombinant strains of porcine epidemic diarrhea virus, United States, 2013. Emerg Infect Dis 20:1735-1738

Vlasova AN, Marthaler D, Wang Q, Culhane MR, Rossow KD, Rovira A, Collins J, Saif LJ (2014) Distinct characteristics and complex evolution of PEDV strains, North America, May 2013-February 2014. Emerg Infect Dis 20:1620-1628

Wang L, Byrum B, Zhang Y (2014a) Detection and genetic characterization of deltacoronavirus in pigs, Ohio, USA, 2014. Emerg Infect Dis 20:1227-1230

Wang L, Byrum B, Zhang Y (2014b) New variant of porcine epidemic diarrhea virus, United States, 2014. Emerg Infect Dis 20:917-919

Wang L, Hayes J, Sarver C, Byrum B, Zhang Y (2016) Porcine deltacoronavirus: histological lesions and genetic characterization. Arch Virol 161:171-175

Wang B, Liu Y, Ji CM, Yang YL, Liang QZ, Zhao P, Xu LD, Lei XM, Luo WT, Qin P, Zhou J, Huang YW (2018a) Porcine deltacoronavirus engages the transmissible gastroenteritis virus functional receptor porcine aminopeptidase $\mathrm{N}$ for infectious cellular entry. J Virol 92(12):e00318-e418

Wang J, Zhang R, Wang J, Han Q, Liu L, Li Y, Yuan W (2018b) Realtime reverse transcription recombinase polymerase amplification assay for rapid detection of porcine epidemic diarrhea virus. $\mathbf{J}$ Virol Methods 253:49-52

Wang L, Su S, Bi Y, Wong G, Gao GF (2018c) Bat-origin coronaviruses expand their host range to pigs. Trends Microbiol 26(6):466-470

Wang Q, Vlasova AN, Kenney SP, Saif LJ (2019) Emerging and reemerging coronaviruses in pigs. Curr Opin Virol 34:39-49

Weiss SR, Navas-Martin S (2005) Coronavirus pathogenesis and the emerging pathogen severe acute respiratory syndrome coronavirus. Microbiol Mol Biol Rev 69:635-664

Whitworth KM, Rowland RRR, Petrovan V, Sheahan M, Cino-Ozuna AG, Fang Y, Hesse R, Mileham A, Samuel MS, Wells KD, Prather RS (2019) Resistance to coronavirus infection in amino peptidase N-deficient pigs. Transgenic Res 28(1):21-32

Williams RK, Jiang GS, Holmes KV (1991) Receptor for mouse hepatitis virus is a member of the carcinoembryonic antigen family of glycoproteins. Proc Natl Acad Sci U S A 88(13):5533-5536

Woo PC, Lau SK, Lam CS, Lau CC, Tsang AK, Lau JH, Bai R, Teng JL, Tsang CC, Wang M, Zheng BJ, Chan KH, Yuen KY (2012) Discovery of seven novel Mammalian and avian coronaviruses in the genus deltacoronavirus supports bat coronaviruses as the gene source of alphacoronavirus and betacoronavirus and avian coronaviruses as the gene source of gammacoronavirus and deltacoronavirus. J Virol 86:3995-4008

Xia L, Dai L, Yang Q (2018a) Transmissible gastroenteritis virus infection decreases arginine uptake by downregulating CAT-1 expression. Vet Res 49(1):95

Xia L, Yang Y, Wang J, Jing Y, Yang Q (2018b) Impact of TGEV infection on the pig small intestine. Virol J 15:102
Xu Z, Zhang Y, Gong L, Huang L, Lin Y, Qin J, Du Y, Zhou Q, Xue C, Cao Y (2019) Isolation and characterization of a highly pathogenic strain of Porcine enteric alphacoronavirus causing watery diarrhoea and high mortality in newborn piglets. Transbound Emerg Dis 66(1):119-130

Xu K, Zhou Y, Mu Y, Liu Z, Hou S, Xiong Y, Fang L, Ge C, Wei Y, Zhang X, Xu C, Che J, Fan Z, Xiang G, Guo J, Shang H, Li H, Xiao S, Li J, Li K (2020) CD163 and pAPN double-knockout pigs are resistant to PRRSV and TGEV and exhibit decreased susceptibility to PDCoV while maintaining normal production performance. Elife 9:e57132

Yang YL, Liang QZ, Xu SY, Mazing E, Xu GH, Peng L, Qin P, Wang B, Huang YW (2019a) Characterization of a novel bat-HKU2like swine enteric alphacoronavirus (SeACoV) infection in cultured cells and development of a $\mathrm{SeACoV}$ infectious clone. Virology 536:110-118

Yang YL, Qin P, Wang B, Liu Y, Xu GH, Peng L, Zhou J, Zhu SJ, Huang YW (2019b) Broad cross-species infection of cultured cells by bat HKU2-related swine acute diarrhea syndrome coronavirus and identification of its replication in murine dendritic cells in vivo highlight its potential for diverse interspecies transmission. J Virol 93(24):e01448-e1519

Yang YL, Yu JQ, Huang YW (2020) Swine enteric alphacoronavirus (swine acute diarrhea syndrome coronavirus): an update three years after its discovery. Virus Res 285:198024

Zhang J (2016) Porcine deltacoronavirus: overview of infection dynamics, diagnostic methods, prevalence and genetic evolution. Virus Res 226:71-84

Zhang J, Tsai YL, Lee PY, Chen Q, Zhang Y, Chiang CJ, Shen YH, Li FC, Chang HF, Gauger PC, Harmon KM, Wang HT (2016) Evaluation of two singleplex reverse transcription-Insulated isothermal PCR tests and a duplex real-time RT-PCR test for the detection of porcine epidemic diarrhea virus and porcine deltacoronavirus. J Virol Methods 234:34-42

Zhang X, Zhu Y, Zhu X, Shi H, Chen J, Shi D, Yuan J, Cao L, Liu J, Dong H, Jing Z, Zhang J, Wang X, Feng L (2017) Identification of a natural recombinant transmissible gastroenteritis virus between Purdue and Miller clusters in China. Emerg Microbes Infect 6:e74

Zou H, Zarlenga DS, Sestak K, Suo S, Ren X (2013) Transmissible gastroenteritis virus: identification of $\mathrm{M}$ protein-binding peptide ligands with antiviral and diagnostic potential. Antiviral Res 99:383-390

Zhou L, Sun Y, Wu JL, Mai KJ, Chen GH, Wu ZX, Bai Y, Li D, Zhou ZH, Cheng J, Wu RT, Zhang XB, Ma JY (2018a) Development of a TaqMan-based real-time RT-PCR assay for the detection of SADS-CoV associated with severe diarrhea disease in pigs. J Virol Methods 255:66-70

Zhou P, Fan H, Lan T, Yang XL, Shi WF, Zhang W, Zhu Y, Zhang YW, Xie QM, Mani S, Zheng XS, Li B, Li JM, Guo H, Pei GQ, An XP, Chen JW, Zhou L, Mai KJ, Wu ZX, Li D, Anderson DE, Zhang LB, Li SY, Mi ZQ, He TT, Cong F, Guo PJ, Huang R, Luo Y, Liu XL, Chen J, Huang Y, Sun Q, Zhang XL, Wang YY, Xing SZ, Chen YS, Sun Y, Li J, Daszak P, Wang LF, Shi ZL, Tong YG, Ma JY (2018b) Fatal swine acute diarrhoea syndrome caused by an HKU2-related coronavirus of bat origin. Nature 556:255-258

Zhou L, Li QN, Su JN, Chen GH, Wu ZX, Luo Y, Wu RT, Sun Y, Lan T, Ma JY (2019a) The re-emerging of SADS-CoV infection in pig herds in Southern China. Transbound Emerg Dis 66:2180-2183

Zhou L, Sun Y, Lan T, Wu R, Chen J, Wu Z, Xie Q, Zhang X, Ma J (2019b) Retrospective detection and phylogenetic analysis of swine acute diarrhoea syndrome coronavirus in pigs in southern China. Transbound Emerg Dis 66:687-695 
Zhu X, Fang L, Wang D, Yang Y, Chen J, Ye X, Foda MF, Xiao S (2017a) Porcine deltacoronavirus nsp5 inhibits interferon- $\beta$ production through the cleavage of NEMO. Virology 502:33-38

Zhu X, Wang D, Zhou J, Pan T, Chen J, Yang Y, Lv M, Ye X, Peng G, Fang L, Xiao S (2017b) Porcine deltacoronavirus nsp5 antagonizes type I interferon signaling by cleaving STAT2. J Virol 91(10):e00003-17

Zhu Y, Liang L, Luo Y, Wang G, Wang C, Cui Y, Ai X, Cui S (2017c) A sensitive duplex nanoparticle-assisted PCR assay for identifying porcine epidemic diarrhea virus and porcine transmissible gastroenteritis virus from clinical specimens. Virus Genes 53:71-76
Zhu X, Liu S, Wang X, Luo Z, Shi Y, Wang D, Peng G, Chen H, Fang L, Xiao S (2018) Contribution of porcine aminopeptidase $\mathrm{N}$ to porcine deltacoronavirus infection. Emerg Microbes Infect 7(1):65

Publisher's note Springer Nature remains neutral with regard to jurisdictional claims in published maps and institutional affiliations. 